\section{Histochemical Demonstration of the Mode of Action of the Alkaloid in Mussel Poisoning}

Ir is generally accepted that the heat-resistant alkaloid which may be extracted from the digestive gland or liver of shellfish in coastal areas where poisoning of humans has occurred is responsible for the clinical picture in these cases. The same poison has been found in the dinoflagellate Gonyaulax catenella ${ }^{1}$ on which the bivalves feed at certain times of the year, and the plankton has, therefore, been held responsible for the production of the toxin.

The exact mode of action and the nature of the poison are as yet unknown ${ }^{2}$. It is described as an alkaloid with muscarine-like actions ${ }^{3}$, and is a potent neurotoxin, but, apart from the central and peripheral neurotoxic actions, Sapeika ${ }^{2}$ has also described a direct depressant action of the toxin on the myocardium and its conducting tissues.

In the present investigation the small amount of mussel extract (2 c.c.) which was used was kindly supplied to us by Dr. N. Sapeika. The extract was prepared from uncooked black mussels according to Dack's ${ }^{4}$ method.

On testing the extract, it was found that $0.6 \mathrm{mgm}$. injected intraperitoneally caused the death of rats weighing $70 \mathrm{gm}$. in a few minutes.

The extract contained $225 \mathrm{mgm}$. of the alkaloid per ml. Various dilutions of this extract were tested on $20-\mu$ thick sections of cold, formalin-fixed rat brain and intercostal muscle. The acetylcholinesterase was demonstrated according to Gomori's ${ }^{5}$ modification of the Koelle method. The sections were pre-incubated in toxin plus buffer for $1 \mathrm{hr}$. before being transferred to the same concentration of the toxin in the substrate mixture. Control sections were pre-incubated in buffer alone. The degree of inhibition obtained and the concentrations used are listed in Table 1. The caudate nucleus was used to assess acetylcholinesterase inhibition.

Table 1. Inhibitory Effect of Musser EXtract on Rat Brain AND INTERCOSTAL MUSCLE

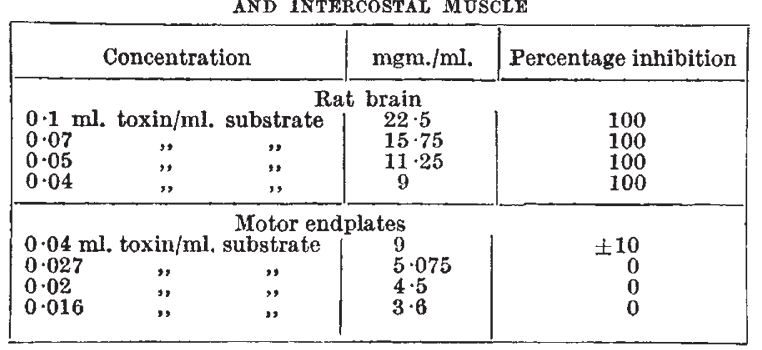

In the concentrations used only slight inhibition was observed in the very strong motor end-plate acetylcholinesterase activity; but, due to the small amount available, this could unfortunately not be tested in a higher concentration-range. However, total inhibition of acetylcholinesterase was produced in the caudate nucleus in the entire concentrationrange of the toxin studied. At the same time, marked inhibition was also observed in the supra-optic neurones.

No inhibition of pseudocholinesterase could be seen in the capillary walls or myelinated areas ${ }^{8}$.

From the above observations, it appears that the alkaloid has a very marked specific acetylcholinesterase inhibitory effect similar to some of the organo-phosphorus compounds. In view of this, it is suggested that future cases of poisoning be treated with one of the oximes such as pyridinealdoxime methiodide?

We are indebted to Dr. N. Sapeika for supplying us with the toxin and to Dr. R. Smit for advice.

This work was supported by a grant from the South African Council for Scientific and Industrial Research.

\section{W. J. PePLER}

E. LOUBSER

Institute for Pathology,

Beatrix Street, Pretoria.

${ }^{1}$ Sommer, H., Whedon, W. F., Kofoid, C. A., and Stohler, R., Arch. Path., 24, 537 (1937).

"Sapeika, N., Arch. Int. Pharmacodyn., 93, 135 (1953).

'Seven, M. J., Ann. Inter. Med., 48, 891 (1958).

- Dack, G. M., "Food Poisoning", 26 (University of Chicago Press, Chicago, 1943).

${ }^{5}$ Gomori, G., "Microscopic Histochemistry - Principles and Practice", first ed., 192 (University of Chicago Press, Chicago, 1952).

'Pepler, W. J., and Pearse, A. G. E., J. Neurochem., 1, 193 (1957). 'Hobbinger, F., Brit. J. Pharmacol., 12, 439 (1957).

\section{Nature of the Leucocytosis-inducing Factor in Plasma}

IT is now well known that fever ${ }^{1}$ and leucocytosis ${ }^{2}$, brought about by typhoid vaccine, are the result of the formation of at least two separate factors and not due to the direct action of vaccine (endotoxin) on the fever centre or on the bone marrow. Fukuda and Matsumoto ${ }^{3}$ have recently demonstrated that the two factors act quite independently of each other and that in adrenalectomized animals, in particular, in spite of the normal occurrence of fever response due to the formation of the endogenous fever factor, leucocytosis fails to occur, and the leucocytosis-inducing factor cannot be detected by the use of passive transfer technique. The formation of the leucocytosis.inducing factor was found to depend solely on the presence of glycocorticoids. Moreover, the formation of this factor after the injection of vaccine could be inhibited by insulin administration, and conversely enhanced in an alloxandiabetic state ${ }^{4}$. It was the object of the present work to examine whether or not this leucocytosis-inducing factor which is detectable in the circulating blood is identical with the 'leucocytosis-promoting factor' of Menkin ${ }^{5}$ which was isolated from sterile exudates.

Typhoid-paratyphoid vaccine for clinical use $(0.1 \mathrm{ml} . / \mathrm{kgm}$.) was first administered intravenously to a rabbit weighing about $2 \mathrm{kgm}$. At the time when a pronounced leucocytosis occurred (usually $8 \mathrm{hr}$. after), the animal was bled from the wellarterized ear vein (25 ml. in $10 \mathrm{~min}$.) and serum was obtained. This serum was found to be capable of inducing a prompt rise in leucocyte counts (pseudoeosinophilia) when given intravenously to a test rabbit $(5 \mathrm{ml} . / \mathrm{kgm}$.). The promptness of the occurrence of leucocytosis without appreciable fever and preceding leucopænia is very characteristic and strongly suggests that this reaction differs greatly from the leucocytic response brought about by the vaccine itself or eventual pyrogenic contamination. The effectiveness of the leucocytosis-inducing factor did not diminish during dialysis through 'Cellophane" tubing against running tap water. Its activity was not reduced by heating at $57^{\circ} \mathrm{C}$. for $30 \mathrm{~min}$., but was completely lost at $100^{\circ} \mathrm{C}$. within $30 \mathrm{~min}$. The leucocytosis-inducing factor, like Menkin's leucocytosis- 